\title{
AN EFFECT OF WELDING TYPE ON THE MECHANICAL
}

\section{PROPERTIES OF WELDING JOINTS}

\section{MOHAMMED SHAALAN ABED FATHI, QAYSHAZIM ISMAEL \& KHALID ABBAS SALEH}

Faculty, Department of Mechanical Engineering, College of Engineering, University of Mosul, Mosul, Iraq

Welding is widely used in the construction of metallic structures. In service, these structures are prone to failure under different types of loadings: static and dynamic. A welding joint should have adequate strength to withstand these type of loadings under the service conditions which is designed to serve within them. This work tries to hold a comparison between two common welding techniques in the local workshops from the point view of strength. The research program included: tensile strength, impact strength, and micro hardness. As received structural bars of mild steel were cut and square butt welded. Two fusion welding techniques was selected: arc welding and oxy-acetylene welding for the availability of their equipment and possibility of using them outdoor. The results obtained during this humble work suggest that from the perspective of tensile strength, oxy-acetylene welding is better than shielded metal arc welding, while the latter is characterized by higher micro hardness and impact strength.
\end{abstract}

KEYWORDS: Mild Steel, Welding Strength, Arc Welding \& Oxy-Acetylene Welding

Received: May 08, 2019; Accepted: May 29, 2019; Published: Jul 08, 2019; Paper Id.: IJMPERDAUG201970

\section{INTRODUCTION}

\subsection{Theoretical Background}

Joining of materials is essential in the design and production of mechanical components. Among the joining methods, welding process is selected to improve mechanical properties, reduce weight, and to reduce manufacturing time (Asibeluo I. S, 2015), Ref no [1]. Welding is widely used in the construction of metallic structures. In service, these structures are prone to failure under different types of loadings: static and dynamic.

According to the force applied, there are two type of welding: fusion welding and pressure welding. Fusion welding needs no force to be applied, the two facing surfaces are melted with or without the addition of a filler metal. In contrast, pressure welding techniques applied an external force that causes a plastic deformation of both facing surfaces, the facing surfaces should be heated to facilitate bonding (Klas Weman, 2003), Ref no [2].

Welding process results in three basic zones across the profile of weldments (Klas Weman, 2003) and (Welding, Brazing, and Soldering, 1993), Ref no[2, 3] :

- $\quad$ The weld-metal (WM) zone: the bonding zone between the two facing surfaces.

- The heat-affected zone (HAZ): the area of the base metal not melted during the welding operation but whose physical properties are altered by the heat induced from the weld joint.

- The base-metal (BM) zone: the area next to the HAZ unaffected by the heat from the welding joint. 


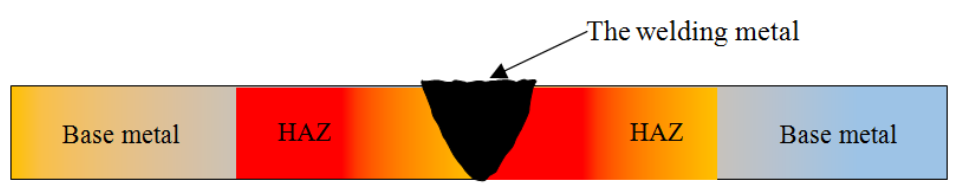

Figure 1: Profile of a Weldment showing BM, HAZ, and WM Zones with Virtual Color Spectrum

The peak temperature and the subsequent cooling rates (Figure 2) determine the HAZ structures, whereas the thermal gradients, the solidification rates, and the cooling rates at the liquid-solid pool boundary determine the solidification structure of the WM zone (Welding, Brazing, and Soldering, 1993), Ref no[3]. In general, the higher the input rate the larger the heat-affected zone.

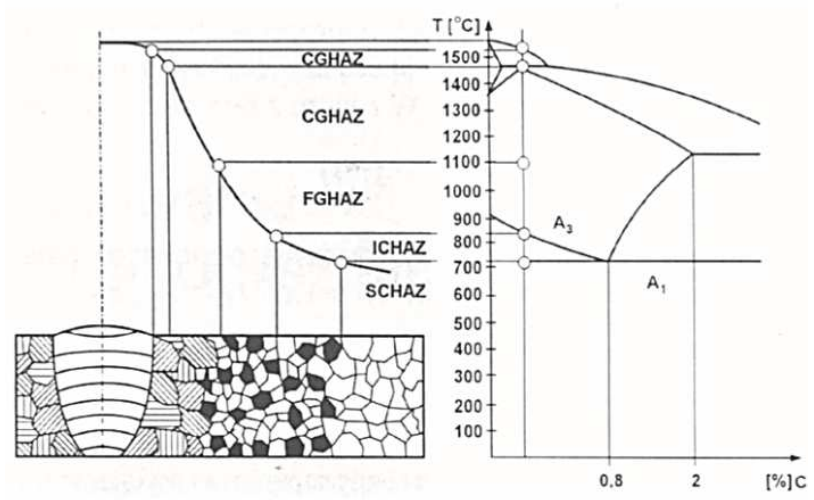

Figure 2: Effect of Temperature Gradient on the Structure of $\mathrm{HAZ}$ (Standard Test Method for Vickers Hardness of Metallic Materials, 1997), Ref no [15]

There are many types of fusion welding such as Shielded Metal Arc Welding (SMAW), Metal Inert Gas welding (MIG welding), oxy-acetylene welding (OAW); Tungsten Inert Gas welding (TIG welding), and laser welding. Friction welding, ultrasonic welding, and cold pressure welding are examples of pressure welding. (Klas Weman, 2003) and (Talabi, S. I, 2014), Ref no [2, 4].

Shielded Metal Arc Welding or stick electrode welding was the predominant form of fusion welding until the beginning of the 1980s. Welding involves striking an arc between the electrode and the work piece, with the heat of the arc melting the electrode (i. e. the filler material), and with the coating melting to form a protective slag. The coating provides: gas, deoxidizers, slag formers, ionizing elements, and alloying elements (Klas Weman, 2003) and (Welding, Brazing, and Soldering, 1993), Ref no [2, 3].

For its high flame temperature, oxyacetylene welding is highly adopted as a welding process. In general, a reaction between acetylene and oxygen gases causes to generate a flame. The heat of the flame melts and joins the metals. OAW does not require electricity, the equipment is easy to transfer, and a welder has considerable control over the rate of heat input, the temperature of the weld zone, and the oxidizing or reducing potential of the welding atmosphere. However, acetylene becomes extremely dangerous if used above 15 pounds pressure, and the welding process is slow if compared with AW processes (Klas Weman, 2003) and ( A. Bhatia), Ref no [2,5]. There are three types of flame: neutral, oxidizing, and reducing flame. 
As stated earlier, weldments subject to different type of loading. The welding joint should have adequate strength to withstand these type of loadings under the service conditions which is designed to serve within them. Much work was achieved in the field of investigating welding strength, either in the form of studying the effect of some parameters of a certain welding technique on the mechanical properties of the welding joint Ref no $[1,4,13,14]$, or comparative studies between two or more of the welding techniques. Ref no[6, 7, 8, 9, 10, 11, 12].

This work tries to hold a comparison between two common welding techniques in the local workshops from the point view of strength: SMAW and OAW. The research program included: tensile strength, impact strength, and micro hardness.

\section{EXPERIMENTAL WORK}

As received structural bars of mild steel-of the chemical composition and microstructure shown in Table 1 and Figure 3-were cut and square butt welded (SS-EN ISO 9692); the cutting process was made under a continuous cooling by water to avoid any microstructural change. The bars are; originally; three meters in length and one centimeter square in cross-sectional area of square shape; they were shaped to match the geometry of the standard specimens of the traditional destructive mechanical tests of weldments including: tensile tests (ASTM E9M-04), impact test (ASTME23. sub size Charpy V-notched specimens), and micro Vickers hardness test(ASTM E92-82).

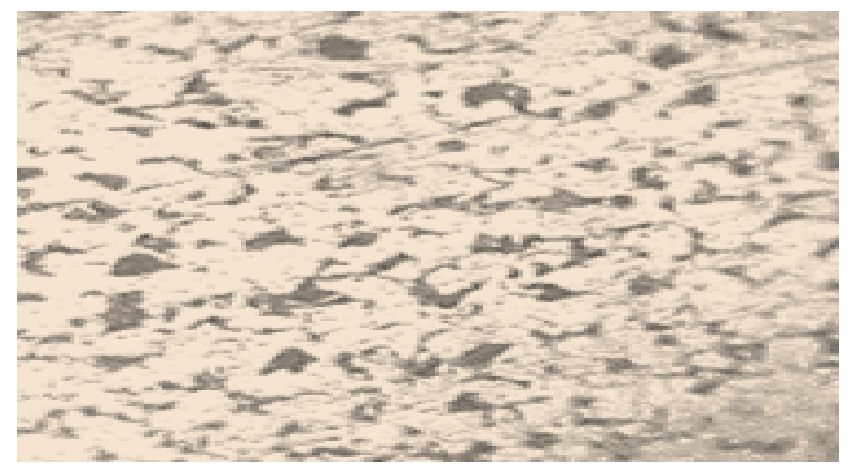

Figure 3: Microstructure of as Received Bar showing the Two Basic Phases of Hypo-Eutectoid Steels: Pearlite in a Matrix of Ferrite.

The Specimen was Grinded, Polished, Polished, and Etched in $2 \%$ Nita (ASTM 23). (X 80)

Two fusion welding techniques was selected: arc welding and oxy-acetylene welding for the availability of their equipment and possibility of using them outdoor. For the arc welding, the electrode is OK 99.9 classified as AWS E6013 with a diameter of $2.4 \mathrm{~mm}$; its chemical analysis is listed in Table 2; it is very close to that of the base metal shown in Table 1. The same electrode type was used as a filler material in OAW. The welding machine is made by Tatian Power Tool, Model: ARC-400 /Germane. Table 3 lists some specifications of this machine.

Table 1: Chemical Composition of the as Received Structural Steel bar using SPECTRO Max X Device

\begin{tabular}{|c|c|c|c|c|c|c|c|c|c|c|}
\hline \% C & \% Si & \% Mn & \%P & \% S & \% Cr & \% Mo & \% Al & \% Ni & \% Cu & \% Fe \\
\hline 0.136 & 0.172 & 0.604 & 0.0205 & 0.0495 & 0.0802 & 0.0169 & 0.0059 & 0.139 & 0.42 & Bal. \\
\hline
\end{tabular}

Table 2: Typical Weld Metal Analysis

\begin{tabular}{|c|c|c|c|c|c|c|c|c|c|}
\hline Element & \% C & \% Mn & \% Si & \% S & \% P & \% Ni & \% Cr & \% Mo & \% V \\
\hline Percentage & 0.10 & 0.60 & 0.50 & 0.030 & 0.035 & 0.30 & 0.20 & 0.20 & 0.05 \\
\hline
\end{tabular}


Table 3: Specification of the Electric arc Welding Machine

\begin{tabular}{|c|c|c|c|c|}
\hline Current (A) & Voltage (V) & Frequency $(\mathbf{H z})$ & Efficiency & Power factor \\
\hline $20-400$ & $220 \pm 15 \%$ & $50 / 60$ & $80 \%$ & 0.73 \\
\hline
\end{tabular}

A set of preliminary specimens were prepared and welded to attain the suitable parameters of the electric power and the flame to be used in the welding process for rotational distortion and other typical defects to be avoided. These specimens were inspected by using x-ray radiation chamber, going through the x-ray plate proved the presence of some welding defects such as cracks and poor penetration. Based on that, the process was modified and the parameters were optimized to be 80 amperes and 40 volt DC which yielded a defect-free welded specimens (see Plate 1).
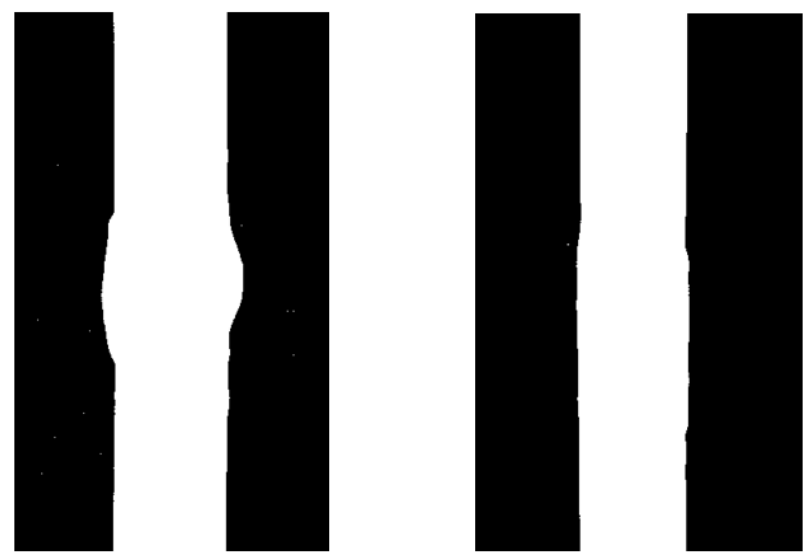

Plate 1: Welded Specimens by both Welding Methods Inspected by x-Ray Radiation Technique showing the Welding Zone and some of the Adjacent Parent Metal

\subsection{Tensile Test}

The tensile test machine is Computer-Controlled Versatile Testing Machine (Type: SANS Testing Machine Co., LTD, Shenzhen, China, Model: WAW-1000). The capacity of the machine is 100 ton with velocity of $13.5 \mathrm{~mm} / \mathrm{minute}$. Nine specimens of weldments and base metal were prepared for the test, the specimen was held in position in a direction perpendicular on the fusion line. A uniaxial force was applied up to the point of breaking. Upon the completion of the test, the measurements are supplied in the form of Microsoft Excel Datasheet with two columns of force and extension.

\subsection{Impact Test}

Three specimens with v-notch of dimensions $55 \times 10 \times 10 \mathrm{~mm}$ were prepared for the impact test in accordance with ASTME23 sub size Charpy V-notched specimens. The v-notch is $2 \mathrm{~mm}$ deep and at $45^{\circ}$ groove angle. The impact test device model is MAT21/ IT3Umade by Brooks Inspection Equipment Ltd, Colchester, England. A specimen is poisoned on an anvil using a guide, then a pendulum weight has a potential energy of $300 \mathrm{~J}$ is allowed to strike the specimen. The energy absorbed by the specimen which is an indicator of its toughness is red on a scale with a resolution of $2 \mathrm{~J}$. 


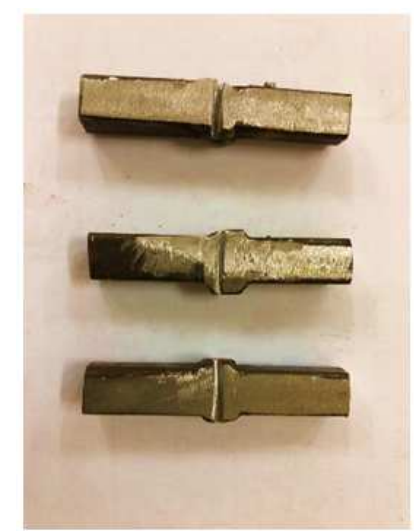

Figure 4: V-notch Samples Prepared for Charpy Test

\subsection{Hardness Test}

Two weldments were prepared to the micro-hardness test according to ASTM E92-82. The surface was grinded and the test specimen was placed on an anvil of a device. The device is WOLPERT AMSLER Type v-tester, Model: D-6100, Germany A square base pyramidal diamond indenter was impressed in the surface using a load of one Kilogram force over a period of $15 \mathrm{~s}$, the angle between the two opposite faces of the pyramid is $136^{\circ}$. The two diagonal of the trace left by the indenter was measured via an optical microscope (figures (5 and 6)). This procedure was repeated across the profile of the weldments $(200 \mathrm{~mm})$ with a step size of $1 \mathrm{~mm}$ from the weld center.

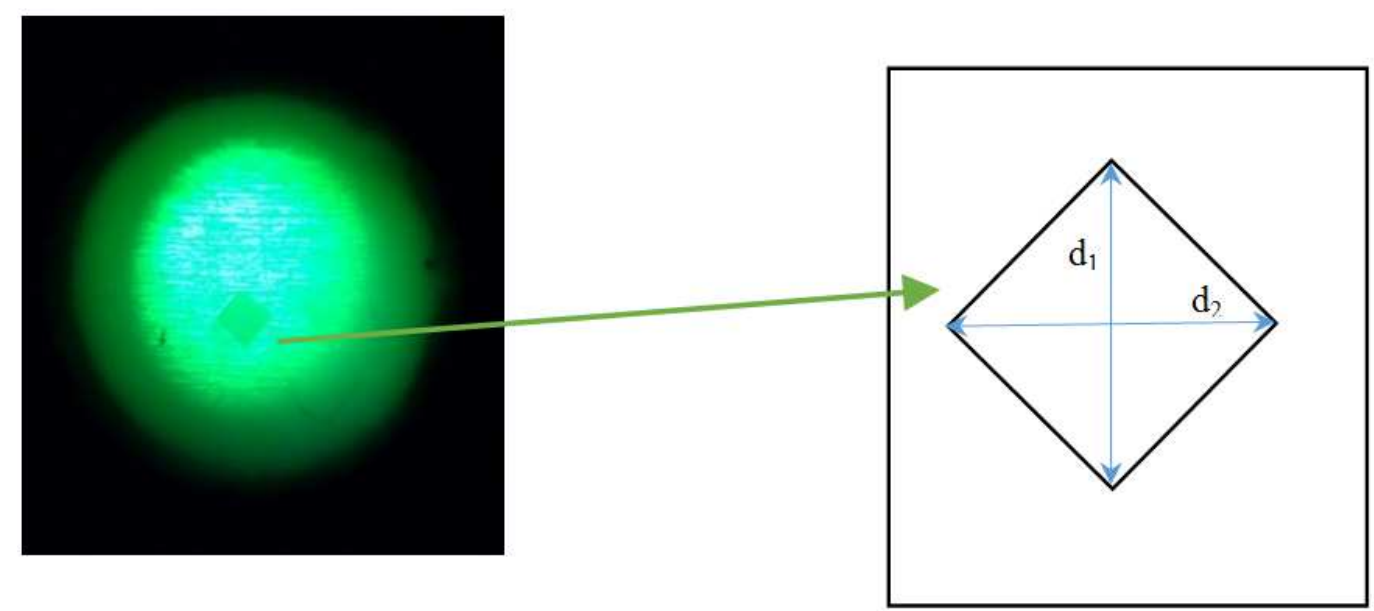

Figure 5: Microscopic view of the Indentation Left by the Test Indenter
Figure 6: Schematic view of the Impression made by the Pyramidal Diamond Indenter

\section{RESULTS AND DISCUSSIONS}

\subsection{Tensile Strength}

After conducting the tests related to the evaluation of the mechanical properties, the measured data was processed and graphed. The average maximum tensile force of the oxy-acetylene welding is $26.1 \mathrm{KN}$, and $23.5 \mathrm{KN}$ for the electric arc welding. The average engineering ultimate tensile stress-in contrast to the true tensile stress which is based on the instantaneous cross-sectional area rather than the original one- was calculated and graphically represented in reference to that of the base metal (Table 4) and Figure 9. The tensile strength of oxyacetylene weldments is slightly higher than that of electric arc weldments, yet the strength of the oxyacetylene weldments is only 59\% of that of the base metal. 
In the acetylene feather, as a part of the oxy-acetylene flame, the excess acetylene is at high temperature and under reducing atmosphere. This leads to complex chemical reactions and the formation of several types of hydrocarbon compounds, which are not negligible for the welding process. Obviously, the flammable gas content affects the tensile strength of weldments (A. Bhatia, 2014), Ref no[6].

Table 4: Engineering Ultimate Tensile Strength Values

\begin{tabular}{|l|c|c|c|}
\hline & Base metal & Arc welding & Oxy-Acetylene Welding \\
\hline UTS(MPa) & 443 & 235.5 & 261 \\
\hline
\end{tabular}

\subsection{Toughness}

The impact tester was calibrated before making the measurements, the energy loss due to friction is $1 \mathrm{~J}$. the energy absorbed by three specimens was taken, averaged, and shown in Figure 11. The energy absorbed in Joules by SMAW specimens is higher than that of OAW. Another confirmation of that behavior can be excluded from the area under stressstrain curves (Figure 7 and 8) which represents an indicator of material toughness.

\subsection{Micro Hardness}

The arithmetic mean of the two diagonals of the indentation was subsequently substituted in Eq. 1 (Z. Sloderbach, J. PaJąk, 2015), Ref no [15], 2015 to find Vickers hardness number. The hardness values for the profile of the weldments are shown in Figures 11 and 12.

$$
\mathrm{HV}=1.854 \frac{\mathrm{P}}{\mathrm{d}^{2}}
$$

The hardness values of OAW are smoothly increased to a peak of 219 before dropping to a hardness value of 178 at the base metal zone. SMAW is characterized by three peaks with values that are significantly higher than their counterpart zones in the OAW. This behavior is valid up to $10 \mathrm{~mm}$ from the welding center, then OAW shows a little higher hardness before levelling to a value of 178 as SMAW do. Mainly, the residual stresses are usually blamed for the variation of the harness across the weld. In addition, metallic inclusion, grain size, and movement of carbon particles and formation of intermetallic compounds and carbides and can also contribute to this hardening (Sudhin Chandran and Nagarajan N. M, 2016) and (Narinder Pal Singh Dhaliwal, Rutash Mittal, 2016) Ref no [9, 11].

\section{CONCLUSIONS AND FUTURE WORK}

The results obtained during this humble work suggest that from the perspective of tensile strength, oxy-acetylene welding is better than shielded metal arc welding, while the latter is characterized by higher micro hardness and impact strength.

The authors would like to do further future research to investigate in details other welding parameters in order to enrich the local and global knowledge in the aspect of joining metals by welding process for being important manufacturing methods.

\section{ACKNOWLEDGEMENT}

The authors would like to acknowledge the effective efforts of the staff of Material Testing Laboratory at Mechanical Engineering Department / Mosul University and Metallurgy Laboratory at Mosul Technical Institute which helped to accomplish this work. 


\section{REFERENCES}

1. Asibeluo I. S, Emifoniye E.," Effect of Arc Welding Current on the Mechanical Properties of A36 Carbon Steel Weld Joints", SSRG International Journal of Mechanical Engineering (SSRG-IJME) - volume 2, Issue 9, September 2015, pp79-87.

2. KlasWeman, "Welding processes handbook", Published by Woodhead Publishing Ltd, Abington Hall, Abington Cambridge CB 1 6AH, England,2003.

3. “Welding, Brazing, and Soldering”, ASM International Handbook, Volume 6, 1993.

4. Talabi, S. I., Owolabi, O. B., Adebisi, J. A., Yahaya, T, "Effect of welding variables on mechanical properties of low carbon steel welded joint”, Advances in Production Engineering \& Management Journal, Volume 9, Number 4, December 2014, pp 181-186, DOI: 10.14743/2014.4.186.

5. A. Bhatia, "Fundamentals of Gas Cutting and Welding", Continuing Education and Development Engineering (cedengineering.com), Course No: D06-002.

6. H. Ates, M. E. Cakır, A. Kurt, I. Uygur, and M. Turker," Investigation of Changes in Mechanical Properties and Microstructures of Mild Steel Joint by Oxy-Hydrogen Welding” 2014, m. 36, No. 11, cc. 1561-1569.

7. Bodude, M. A. and Momohjimoh, I. "Studies on Effects of Welding Parameters on the Mechanical Properties of Welded LowCarbon Steel". Journal of Minerals and Materials Characterization and Engineering, 3, 2015, pp 142-153, DOI: 10.4236/jmmce.2015.33017.

8. Shameel K, Dr NM Nagarajan, "Comparative studies on joint design of mild steel using MAW and MIG welding”, International Journal of Latest Engineering and Management Research (IJLEMR), Volume 02, Issue 05, May 2017, PP. 27-37

9. Sudhin Chandran and Nagarajan N. M, "Comparative studies on joining of structural steels using MIG and arc welding processes”, International Journal of Recent Scientific Research, Vol. 7, Issue, 7, July, 2016, pp. 12405-12410,

10. Radha Raman Mishra, Visnu Kumar Tiwari and Rajesha S., "A study of tensile strength of MIG and TIG welded dissimilar joints of mild steel and stainless steel”, International Journal of Advances in Materials Science and Engineering (IJAMSE) Vol.3, No.2, April 2014, pp. 23-32, DOI : 10.14810/ijamse.2014.3203.

11. Narinder Pal Singh Dhaliwal, Rutash Mittal, Salwinder Gill, ParasKhullar, "Comparative Evaluation of Impact Strength of Dissimilar Metal Weld between T91 and 304SS Prepared by SMAW and GTAW Techniques”, Indian Journal of Science and Technology, Vol 9(39), October 2016, DOI: 10.17485/ijst/2016/v9i39/101403.

12. AkashSrivastava, Sumeet Sekhar, AyushPandey, "Analysis of Welding Joints and Processes", International Conference on Advances in Emerging Technology, 2016, pp.20-26.

13. Yunus, Mohammed., \& Alsoufi, M. S. (2015). A statistical analysis of joint strength of dissimilar aluminium alloys formed by friction stir welding using taguchi design approach, anova for the optimization of process parameters. IMPACT: International Journal of Research in Engineering \& Technology (IMPACT: IJRET), 3(7), 63-70.

14. Brajesh Kumar Singh, A. K. Jha, Pravin K. Singh, "Effects of Joint Geometries on Welding of Mild Steel by Shielded Metal Arc Welding (SMAW)", International Research Journal of Engineering and Technology (IRJET), Volume: 02, Issue: 07, Oct2015, pp.95-100.

15. O. M. Ikumapayi, I. P. Okokpujie, S. A. Afolalu, O. O. Ajayi, E. T. Akilabil, O. P Bodunde, "Effects of Quenchants on Impact Strength of Single-Vee Butt Welded Joint of Mild Steel”, IOP Conf. Series: Materials Science and Engineering 391 (2018) 012007, pp.1-10, DOI:10.1088/1757-899X/391/1/012007, 
16. Standard Test Methodfor Vickers Hardness of Metallic Materials, American Society for Testing and Material, Designation: E92-82, 1997.

17. Z. Śloderbach, J. PaJąk, "Determination of Ranges of Components of Heat Affected Zone Including Changes of Structure”, Archive of Metallurgy and Materials, Volume 60, Issue 4, 2015, PP.2607-2612, DOI: 201515/amm-2015-0421,

\section{APPENDICES}

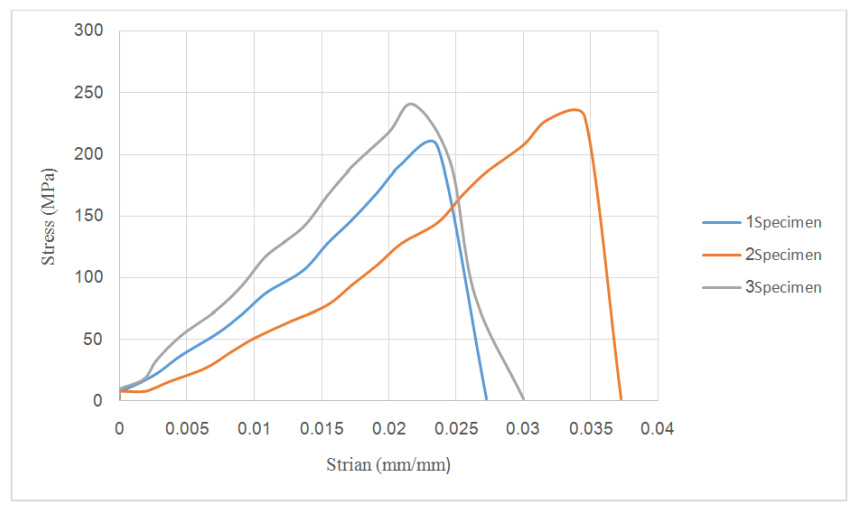

Figure 7: Stress-Strain diagram for Three Specimens Welded by SMAW

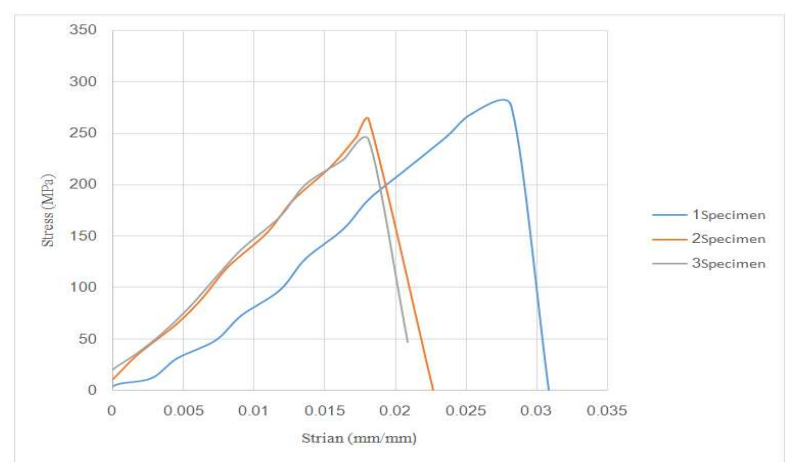

Figure 8: Stress-Strain diagram for Three Specimens welded by OAW

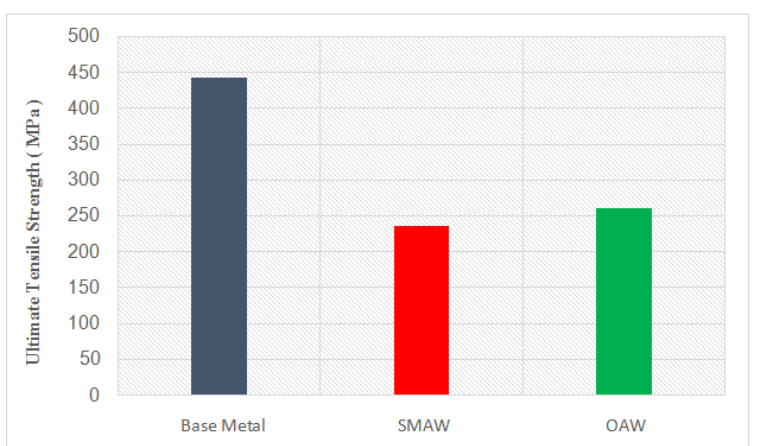

Figure 9: Average Ultimate Tensile Strength of BM, SMAW, and OAW. SMAW 


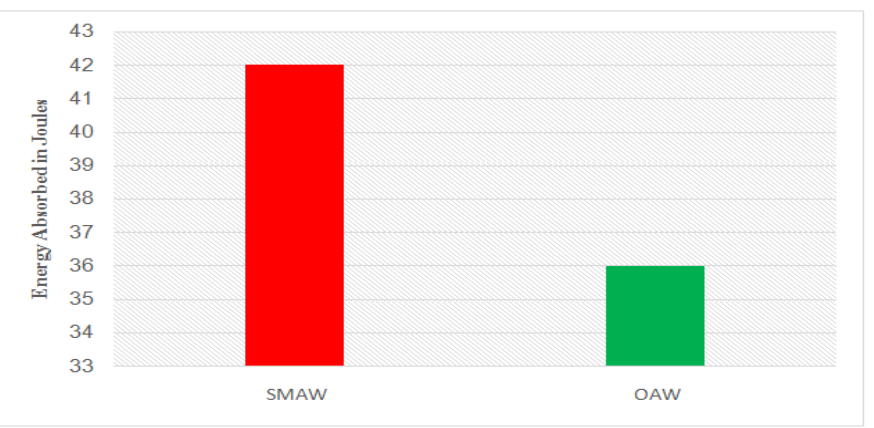

Figure 10: Average Impact Strength of OAW and SMAW

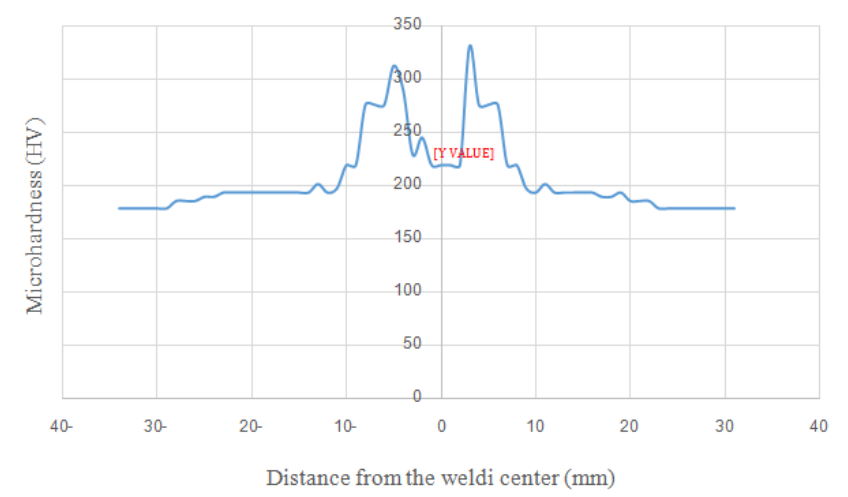

Figure 11: Hardness profile of SMAW

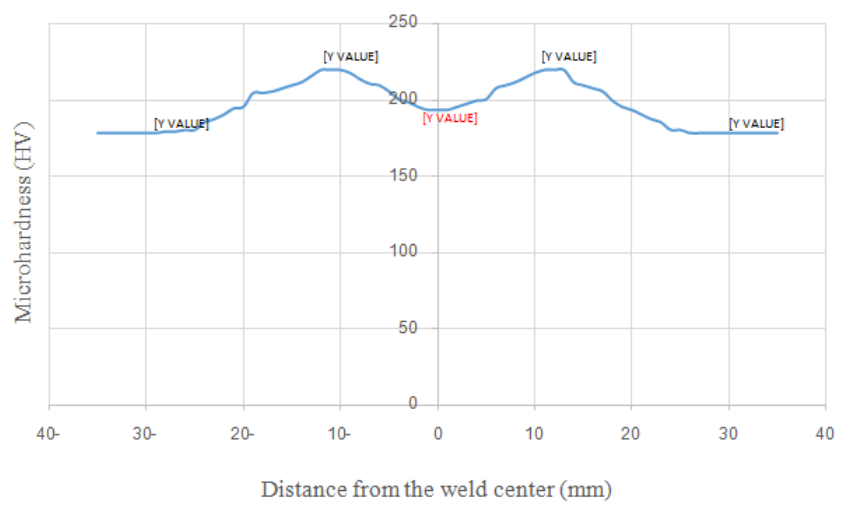

Figure 12: Hardness Profile of OAW 
